\title{
Exercise-induced flow limitation, dynamic hyperinflation and exercise capacity in patients with bronchial asthma
}

\author{
E.N. Kosmas*, J. Milic-Emili\#, A. Polychronaki*, I. Dimitroulis*, S. Retsou*, M. Gaga*, A. Koutsoukou*, \\ Ch. Roussos*, N.G. Koulouris*
}

Exercise-induced flow limitation, dynamic hyperinflation and exercise capacity in patients with bronchial asthma. E.N. Kosmas, J. Milic-Emili, A. Polychronaki, I. Dimitroulis, S. Retsou, M. Gaga, A. Koutsoukou, Ch. Roussos, N.G. Koulouris. (C) ERS Journals Ltd 2004.

ABSTRACT: It is known that, in stable asthmatics at rest, tidal expiratory flow limitation (EFL) and dynamic hyperinflation (DH) are seldom present. This study investigated whether stable asthmatics develop tidal EFL and DH during exercise with concurrent limitation of maximal exercise work rate (WRmax).

A total of 20 asthmatics in a stable condition and aged $32 \pm 13$ yrs (mean \pm SD) with a forced expiratory volume in one second (FEV1) of $101 \pm 21 \%$ of the predicted value were studied. Only three patients exhibited an FEV1 below the normal limits. On a first visit, patients performed a symptom-limited incremental $\left(20 \mathrm{~W} \cdot \mathrm{min}^{-1}\right)$ bicycle exercise test. On the second visit, the occurrence of EFL (using the negative expiratory pressure technique) and DH (via reduction in inspiratory capacity) were assessed at rest and when cycling at 33, 66 and $90 \%$ of their predetermined WRmax. FEV1 was measured to detect exercise-induced asthma, 5 and 15 min after stopping exercise at $90 \%$ WRmax.

Only one patient showed EFL at rest, whereas 13 showed EFL and DH during exercise. In these 13 asthmatics, exercise capacity was significantly reduced (WRmax $75 \pm 9 \%$ pred) compared to the seven non-EFL patients (WRmax $95 \pm 13 \%$ pred). Moreover, a significant correlation of WRmax (\% pred) to the change in inspiratory capacity (percentage of resting value) from rest to $90 \%$ WRmax was found. Tidal EFL during exercise was not associated with exercise-induced asthma, which was detected in only three patients.

In conclusion, tidal expiratory flow limitation and dynamic hyperinflation during exercise are common in stable asthmatics with normal spirometric results and without exercise-induced asthma, and may contribute to reduction in exercise capacity.

Eur Respir J 2004; 24: 378-384.
*Respiratory Function Laboratory, Dept of Respiratory Medicine, Athens University Medical School, Sotiria Hospital, Athens, Greece. "Meakins-Christie Laboratories, McGill University, Montreal, Canada.

Correspondence: E.N. Kosmas

Dept of Respiratory Medicine

University of Athens Medical School

"Sotiria" Chest Diseases Hospital

152 Mesogion Ave

Athens, GR-115 27

Greece.

Fax: 302107770423

E-mail: enkosmas@mland.gr

Keywords: Asthma

dynamic hyperinflation

exercise

flow limitation

Received: October 82003

Accepted after revision: March 252004

This study was partly supported by the Thorax Foundation Athens, Greece.
Bronchial asthma is a common disorder characterised by chronic airway inflammation in response to various stimuli and by recurrent episodes of symptoms (cough, wheezing and dyspnoea) accompanied by airway obstruction, which is partly or completely reversible, either spontaneously or after treatment [1]. Several recent articles have shown that asthmatic patients, even when asymptomatic and with mild asthma, may show reduced exercise capacity [2-7]. It is not clear whether this reduction should be attributed to cardiorespiratory limitation or peripheral muscle deconditioning. However, MURARIU et al. [2] reported that, in patients with asthma as well as chronic obstructive pulmonary disease (COPD), there was a close correlation between exercise capacity and resting inspiratory capacity (IC), and suggested that hyperinflation might play a role in limiting exercise performance.

Tidal expiratory flow limitation (EFL) is present in a significant proportion of patients with COPD during resting breathing, resulting in dynamic hyperinflation (DH), reflected in a decreased IC [2, 8, 9]. During exercise, EFL occurs in almost all COPD patients [10], and is associated with impaired exercise performance due to $\mathrm{DH}$ [9-11]. In contrast, the majority of stable asthmatic patients do not exhibit EFL during resting breathing $[12,13]$ and there are no reliable data concerning EFL during exercise.
Accordingly, the principal objective of the present study was to assess tidal EFL and DH during exercise in stable asthmatic patients, and to determine their role in limiting exercise capacity. In addition, the presence of exerciseinduced asthma (EIA) was assessed in order to investigate whether or not it was associated with tidal EFL and DH during exercise.

\section{Methods}

\section{Subjects}

In total, 20 consecutive patients ( 13 female) aged $32 \pm 13$ yrs (mean $\pm \mathrm{sD}$ ) were recruited from the Asthma Outpatient Clinic of Sotiria Hospital (Athens, Greece) and agreed to participate in the study. Diagnosis was made according to Global Initiative for Asthma criteria [1]. The patients fulfilled the following inclusion criteria: 1) age $<60 \mathrm{yrs}$; 2) stable condition (no infection or other type of exacerbation during the past 2 months); 3) no clinical or laboratory evidence of any other cardiorespiratory disease; 4) lifelong nonsmoking status; and 5) body weight within normal limits. All patients were studied on two occasions, 1-2 days apart. On each occasion, the 
patients refrained from using inhaled bronchodilators for $\geqslant 8 \mathrm{~h}$ prior to the investigation, except for patients who were being treated with long-acting bronchodilators, who were asked to refrain from their use for $\geqslant 24 \mathrm{~h}$. The therapeutic regimen at the time of the study did not include inhaled corticosteroids, except in three patients with moderate-tosevere asthma. These three patients were asked to refrain from the use of inhaled steroids for the 5 days prior to the measurements. The study was approved by the Institutional Ethics Committee of Sotiria Hospital and informed consent was obtained from all patients.

On the morning of the first visit, all patients underwent spirometry (Benchmark Pulmonary Function Testing; P.K. Morgan Ltd, Rainham, UK) according to recommended guidelines [14]. The reference values used were those of QuANJer et al. [14]. Predicted IC was calculated as the difference between predicted total lung capacity and predicted functional residual capacity.

All patients then performed an incremental symptomlimited exercise test on an electrically braked cycle ergometer (Model A1; Instrumenten Lode N.V., Groningen, The Netherlands) and using an automated cardiopulmonary exercise testing system (Benchmark Exercise Test; P.K. Morgan Ltd). After a 3-min warm-up period with unloaded cycling, patients cycled at 50-60 revolutions $\cdot \mathrm{min}^{-1}$, with the external power increased every minute in $20-\mathrm{W}$ steps to the limit of their tolerance. Patients were verbally encouraged to reach their maximum during the exercise test [15]. Maximal power output (WRmax) was defined as the highest power output maintained for $\geqslant 30 \mathrm{~s}$. Oxygen saturation, electrocardiogram and blood pressure were monitored continuously via a vital signs monitor attached to the metabolic chart (Monitor M-1; P.K. Morgan Ltd). The breath-by-breath inspiratory and expiratory airflows and fractions of expired oxygen and carbon dioxide were used to calculate oxygen uptake $\left(V^{\prime} \mathrm{O}_{2}\right)$ and carbon dioxide output. These metabolic measurements, together with ventilation $\left(V^{\prime} \mathrm{E}\right)$, tidal volume, respiratory frequency and cardiac frequency $(f \mathrm{C})$, were recorded continuously and a 10-breath average at the end of each 1-min step was used for data analysis. The predicted values used were those of JONES [16]. Maximal voluntary ventilation (MVV) was calculated as the product of forced expiratory volume in one second (FEV1) and 35.

Prior to exercise testing, subjects were familiarised with the Borg scale [17], and its end points were anchored such that 0 represented no breathlessness and 10 was the most severe breathlessness that they have ever experienced or could imagine experiencing. By pointing to the Borg scale, patients rated their perceived dyspnoea at peak exercise.

On the second visit, EFL was assessed at rest in the upright sitting position on the bicycle via a method based on the application of an negative expiratory pressure (NEP) at the airway opening during tidal expiration [8, 10]. A flanged plastic mouthpiece was connected in series to a pneumotachograph (Erich Jaeger Gmbh \& Co., Höchberg, Germany) and a T-tube. One side of the T-tube was open to the atmosphere, whereas the other side was equipped with a oneway pneumatic valve, which allows for the subject to be rapidly switched to negative pressure generated by a vacuum cleaner [10]. The pneumatic valve consisted of an inflatable balloon connected to a gas cylinder filled with helium and a manual pneumatic controller. The latter permits remotecontrolled balloon deflation, which is accomplished quickly (30-60 ms) and quietly, allowing rapid exposure to NEP. The NEP (usually set at $-3--3.5 \mathrm{cmH}_{2} \mathrm{O}$ ) can be adjusted via a potentiometer on the vacuum cleaner. Airflow was measured using the heated pneumotachograph, and the pressure at the airway opening was simultaneously measured through a side port on the mouthpiece. Volume was obtained by numerical integration of the flow signal. An increase in expiratory flow with NEP, relative to the preceding breath, was taken as indicating the absence of EFL (NFL). In contrast, when expiratory flow with NEP did not increase, compared to the preceding control breath, during the entire or a portion of the test breath, EFL was considered to be present. The absence of overall tidal EFL, as measured using the NEP method, does not preclude the presence of regional EFL within the lungs.

The presence of tidal EFL was assessed at rest, sitting on the bicycle ergometer, and while cycling at 33,66 and $90 \%$ of the predetermined WRmax. Under all conditions, three or four NEP tests were performed, followed by two or three IC manoeuvres. In all instances, Borg score was also assessed, all measurements being performed after 3-5 min of resting breathing or pedalling in order to ensure attainment of a steady-state breathing pattern. The consecutive exercise tests were carried out at intervals of $40-45 \mathrm{~min}$ in order to avoid carry-on effects of EIA, if present, on the subsequent exercise test [18].

FEV1 was measured 5 and $15 \mathrm{~min}$ after the end of the exercise at $90 \%$ WRmax, in order to assess whether EIA was present. A fall in FEV1 of $\geqslant 15 \%$ of the pre-exercise value was taken as indicating EIA [19].

\section{Statistical analysis}

Results are expressed as mean \pm SD. Comparison of differences in IC and Borg score between rest and various levels of exercise in EFL and NFL patients were made using a paired t-test. Similarly, all comparisons between EFL and NFL patients (demographics, resting lung function, WRmax (\% pred) and maximal $V^{\prime} \mathrm{O}_{2}\left(V^{\prime} \mathrm{O}_{2}\right.$, max $)$ ) were made using an unpaired t-test. One-way repeated-measures analysis of variance and an all-pairwise multiple comparison procedures test (Tukey's test) were used to assess the significance of changes in IC and Borg score at each level of exercise intensity in EFL and NFL subjects. Pearson's correlation coefficients and linear regression analyses were used to assess the strength of association between variables. A p-value of $<0.05$ was taken as significant.

\section{Results}

Anthropometric and resting spirometric data are shown in table 1. There was no significant difference between EFL and NFL patients with respect to their anthropometric data and resting lung function. Only three patients exhibited an FEV1 and peak expiratory flow (PEF) below the normal limits (fig. 1), whereas, in the remaining 17 patients, FEV1 and PEF were within normal limits. According to current criteria of classification [1], 17 patients had intermittent or mild persistent asthma (FEV1 or PEF $\geqslant 80 \%$ pred; PEF variability $<30 \%$ ), one moderate persistent asthma (FEV1 or PEF $60-80 \%$ pred; PEF variability $>30 \%$ ) and two severe persistent asthma (FEV1 or PEF $\leqslant 60 \%$ pred; PEF variability $>30 \%$ ). All patients showed little or no chronic dyspnoea (Medical Research Council (MRC), UK, score 0-1). Exercise capacity and peak exercise cardiorespiratory responses are shown in table 2. Eight patients showed a reduction in exercise capacity (WRmax 79-58\% pred; $V^{\prime} \mathrm{O}_{2}$, $\max 77-56 \%$ pred) according to American Thoracic Society/American College of Chest Physicians guidelines [15]. The slope of the increase in $V^{\prime} \mathrm{O}_{2}$ relative to the increase in work rate and the anaerobic threshold were within normal limits.

Only one subject exhibited EFL at rest. Three more exhibited EFL at 33\% WRmax, five at $66 \%$ and four at $90 \%$, whereas seven asthmatics remained NFL $\leqslant 90 \% \mathrm{WR}$ max 
Table 1.-Anthropometric characteristics and spirometric data of stable asthmatic patients stratified by expiratory flow limitation (EFL) and non-EFL (NFL)

\begin{tabular}{lccc}
\hline & Total & NFL & EFL \\
\hline Age yrs & $32 \pm 13(18-59)$ & $33 \pm 12$ & $32 \pm 14$ \\
Males/females n & $7 / 13$ & $2 / 5$ & $5 / 8$ \\
Height cm & $166 \pm 10(150-187)$ & $168 \pm 12$ & $166 \pm 9$ \\
BMI kg·m & $23 \pm 4(17-30)$ & $21 \pm 3$ & $24 \pm 4$ \\
MRC score & $0.55 \pm 0.51(0-1)$ & $0.43 \pm 0.53$ & $0.62 \pm 0.51$ \\
IC \% pred & $96 \pm 21(66-131)$ & $96 \pm 23$ & $96 \pm 21$ \\
FEV1\% pred & $101 \pm 21(52-134)$ & $108 \pm 16$ & $97 \pm 23$ \\
FVC \% pred & $112 \pm 17(84-135)$ & $112 \pm 14$ & $111 \pm 19$ \\
FEV1/FVC \% & $77 \pm 12(50-84)$ & $81 \pm 8$ & $75 \pm 14$ \\
FEV1/FVC \% pred & $90 \pm 14(62-112)$ & $95 \pm 10$ & $87 \pm 15$ \\
PEF \% pred & $104 \pm 23(62-146)$ & $117 \pm 21$ & $99 \pm 21$ \\
FEF25-75\% \% pred & $76 \pm 35(15-145)$ & $86 \pm 27$ & $70 \pm 38$ \\
FEF50\% \% pred & $80 \pm 31(23-117)$ & $89 \pm 24$ & $75 \pm 30$ \\
FEF75\% \% pred & $75 \pm 39(12-108)$ & $87 \pm 22$ & $69 \pm 36$ \\
\hline
\end{tabular}

Data are presented as mean \pm SD with range in parenthesis. All differences were nonsignificant. BMI: body mass index; MRC: Medical Research Council (UK); IC: inspiratory capacity; \% pred: percentage of the predicted value; FEV1: forced expiratory volume in one second; FVC: forced vital capacity; PEF: peak expiratory flow; FEF25-75\%: forced mid-expiratory flow; FEF $50 \%$ : forced expiratory flow when $50 \%$ of FVC has been exhaled; FEF $75 \%$ : forced expiratory flow when $75 \%$ of FVC has been exhaled.
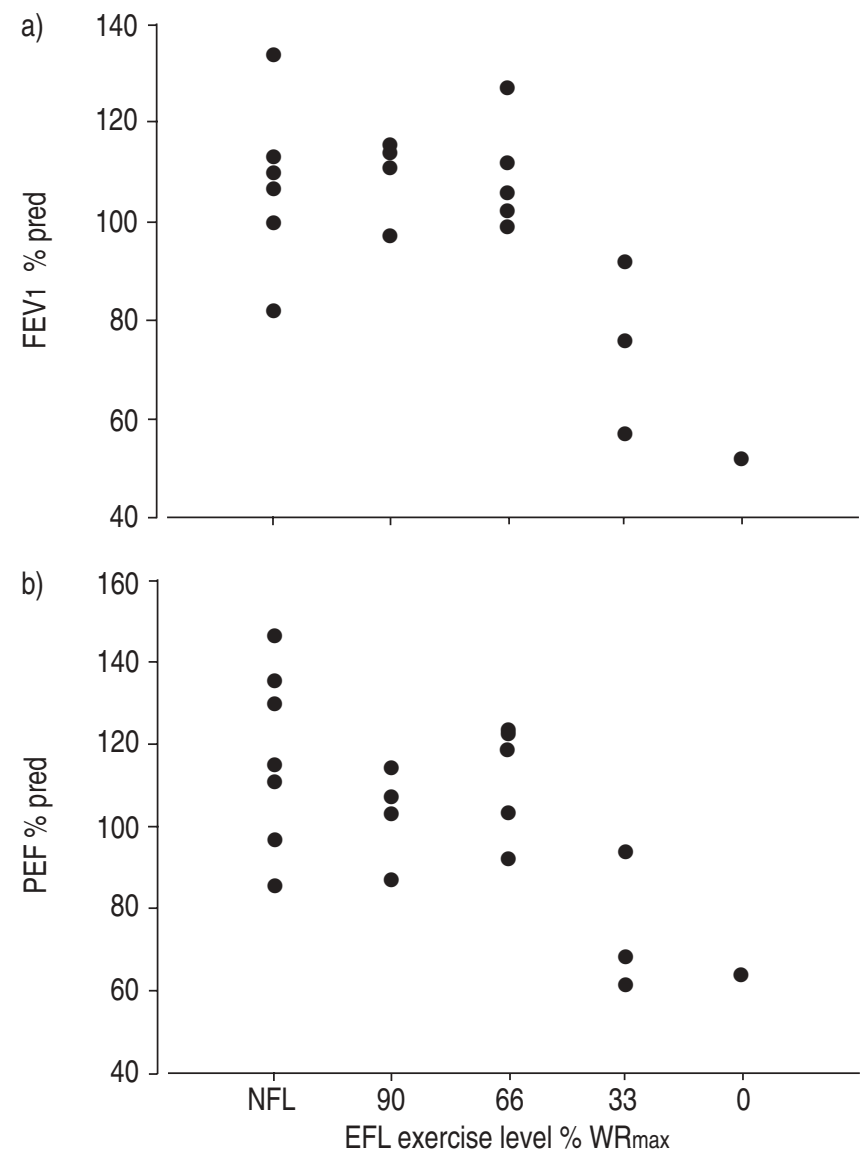

Fig. 1.-a) Forced expiratory volume in one second (FEV1) and b) peak expiratory flow (PEF) in asthmatic patients stratified according to the exercise level at which they first exhibited expiratory flow limitation (EFL). Each data point represents a single patient. NFL: non-EFL up to $90 \%$ maximal work rate (WRmax).
Table 2.-Maximal exercise capacity and peak exercise cardiorespiratory responses in stable asthmatic patients

\begin{tabular}{|c|c|c|}
\hline & Mean \pm SD & Range \\
\hline WRmax W & $133 \pm 30$ & $80-180$ \\
\hline WRmax \% pred & $82 \pm 14$ & $58-124$ \\
\hline$V^{\prime} \mathrm{O}_{2}, \max \mathrm{L} \cdot \min ^{-1}$ & $1.87 \pm 0.44$ & $0.97-2.97$ \\
\hline$V^{\prime} \mathrm{O}_{2}, \max \mathrm{mL} \cdot \min ^{-1} \cdot \mathrm{kg}$ body weight ${ }^{-1}$ & $30 \pm 7$ & $20-43$ \\
\hline$V^{\prime} \mathrm{O}_{2}, \max \%$ pred & $81 \pm 12$ & $56-105$ \\
\hline AT $\%$ pred $V^{\prime} \mathrm{O}_{2}, \max$ & $49 \pm 4$ & $42-62$ \\
\hline$V^{\prime} \mathrm{E}, \max \mathrm{L} \cdot \mathrm{min}^{-1}$ & $59 \pm 15$ & $35-84$ \\
\hline$V^{\prime} \mathrm{E}, \max \%$ pred & $81 \pm 21$ & $44-142$ \\
\hline$V^{\prime} \mathrm{E}, \max / \mathrm{MVV} \%$ & $53 \pm 14$ & $33-77$ \\
\hline$V \mathrm{~T}, \max \mathrm{L}$ & $1.787 \pm 0.429$ & $1.094-2.730$ \\
\hline$V \mathrm{~T}, \max \%$ pred & $92 \pm 24$ & $52-164$ \\
\hline$f R, \max$ breaths $\cdot \min ^{-1}$ & $33 \pm 6$ & $22-44$ \\
\hline$f R$, max $\%$ pred & $103 \pm 43$ & $57-233$ \\
\hline $\mathrm{SP}, \mathrm{O}_{2} \%$ & $97 \pm 1$ & $94-99$ \\
\hline$f \mathrm{C}, \max$ beats $\cdot \min ^{-1}$ & $166 \pm 14$ & $130-183$ \\
\hline$f \mathrm{C}, \max \%$ pred & $89 \pm 7$ & $79-112$ \\
\hline$V^{\prime} \mathrm{O}_{2} / f \mathrm{C} \mathrm{mL} \cdot \mathrm{min}^{-1} \cdot$ beat $^{-1}$ & $11.3 \pm 2.6$ & $6.1-17.3$ \\
\hline$V^{\prime} \mathrm{O}_{2} / f \mathrm{C} \%$ pred & $91 \pm 13$ & $64-116$ \\
\hline Borg dyspnoea score & $2.95 \pm 1.81$ & $0-6$ \\
\hline
\end{tabular}

WRmax: maximal work-rate; \% pred: percentage of the predicted value; $V^{\prime} \mathrm{O}_{2}$,max: maximal oxygen uptake; AT: anaerobic threshold; $V^{\prime} \mathrm{E}$,max: maximal minute ventilation; MVV: maximal voluntary ventilation; $V$ T,max: maximal tidal volume; $f R$,max: maximal respiratory frequency; $S \mathrm{P}, \mathrm{O}_{2}$ : arterial oxygen saturation measured by pulse oximetry; $f \mathrm{C}$, max: maximal cardiac frequency; $V^{\prime} \mathrm{O}_{2} / f \mathrm{C}$ : oxygen pulse.

(table 3). Exercise capacity was significantly reduced in the 13 EFL patients (WRmax $75 \pm 9 \%$ pred; $V^{\prime} \mathrm{O}_{2}$, max $77 \pm 11 \%$ pred) compared to the seven NFL patients (WRmax $95 \pm 13 \%$ pred, $\mathrm{p}<0.001 ; V^{\prime} \mathrm{O}_{2}$, max $92 \pm 8 \%$ pred, $\mathrm{p}=0.003$ ).

The patient who exhibited EFL at rest showed low FEV1 and PEF (52 and 64\% pred, respectively) and exhibited DH at rest, as reflected in the reduced IC (75\% pred). FEV1 and PEF were also below the normal range in two of the three patients who developed EFL at 33\% WRmax (fig. 1). In contrast, in the other 17 asthmatics, FEV1 and PEF were within the normal limits. Nevertheless, one of these 17 patients developed EFL at 33\% WRmax, five at $66 \%$ and another four at $90 \%$. Seven of the patients with normal spirometric results remained $\mathrm{NFL} \leqslant 90 \% \mathrm{WRmax}$.

As shown in table 4, the resting IC did not differ significantly between EFL and NFL patients. However, during exercise, IC decreased in EFL patients, whereas it increased in NFL patients. Significant differences in IC between EFL and NFL patients were observed at 66 and $90 \%$ WRmax ( $\mathrm{p}=0.05$ and $\mathrm{p}=0.03$, respectively). At $90 \%$ WRmax, IC decreased significantly (by $464 \pm 396 \mathrm{~mL}$ ) in all 13 patients who developed EFL during exercise, whereas, in six of the seven NFL patients, it increased $(242 \pm 359 \mathrm{~mL})$, although not significantly. The percentage change in IC from rest to $90 \%$ WRmax was $-18 \pm 12 \%$ in EFL patients $(\mathrm{p}<0.001)$

Table 3.-Stratification of asthmatic patients according to expiratory flow limitation (EFL)

\begin{tabular}{lcc}
\hline Exercise level \% WRmax & EFL patients & NFL patients \\
\hline 0 & 1 & 19 \\
33 & 4 & 16 \\
66 & 9 & 11 \\
90 & 13 & 7 \\
\hline
\end{tabular}

Data are presented as $\mathrm{n}$ unless otherwise stated. WRmax: maximal work-rate; NFL: non-EFL. " : assessed using the negative expiratory pressure technique; ${ }^{\imath}$ : rest. 
Table 4.-Changes in inspiratory capacity at rest and during exercise in expiratory flow limitation (EFL) and non-EFL (NFL) patients

\begin{tabular}{lccc}
\hline & NFL patients & EFL patients & p-value \\
\hline Subjects n & 7 & 13 & \\
Inspiratory capacity L & & & \\
$\quad$ Rest & $2.53 \pm 1.03$ & $2.40 \pm 0.62$ & $\mathrm{NS}$ \\
$33 \%$ WRmax & $2.66 \pm 1.10$ & $2.22 \pm 1.10$ & $\mathrm{NS}$ \\
$66 \%$ WRmax & $2.84 \pm 1.15$ & $2.07 \pm 0.51$ & 0.05 \\
$90 \%$ WRmax & $2.77 \pm 1.13$ & $1.94 \pm 0.45$ & 0.03 \\
p-value & $\mathrm{NS}$ & $<0.001$ & \\
\hline
\end{tabular}

Data are presented as mean \pm SD. WRmax: maximal work-rate. NS: nonsignificant. " : unpaired t-test; ": one-way repeated-measures analysis of variance.

and $10 \pm 16 \%$ in NFL patients (NS). The ICs at rest and at different exercise levels in NFL and EFL patients are depicted in figure 2. According to one-way analysis for repeated measures and all-pairwise multiple comparisons (Tukey's test), in the EFL patients, there was a significant progressive decrease in IC from rest to 66 and $90 \%$ WRmax $(\mathrm{p}<0.001$ for both). In contrast, in the NFL patients, IC increased with increasing exercise level, but the changes were not significant.

Eight of the 20 asthmatics exhibited exercise limitation, as reflected by values of WRmax (fig. 3) and $V^{\prime} \mathrm{O}_{2}$, max below the normal limits. Three of these patients (with WRmax ranging $58-65 \%$ pred) were those with abnormal resting spirometric results and EFL either at rest or at 33\% WRmax. The remaining five subjects with exercise limitation (WRmax $71-79 \%$ pred) showed normal resting spirometric results, although all of them exhibited EFL during exercise (33-90\% WRmax). In the other five patients who developed EFL during exercise, WRmax was in the lower limits of normal ( $80-86 \%$ pred). In contrast, in all NFL patients, WRmax was $>86 \%$ pred. In addition, in the 13 asthmatics who exhibited EFL at rest or during exercise, a significant correlation was found between exercise capacity (WRmax (\% pred)) and the exercise level at which the asthmatics first exhibited tidal EFL ( $r=0.82$ ) (fig. 3).

The presence of EFL, which implies DH with increased inspiratory work due to intrinsic positive end-expiratory pressure and impaired inspiratory muscle function [8, 9], possibly associated with impaired haemodynamics [20],

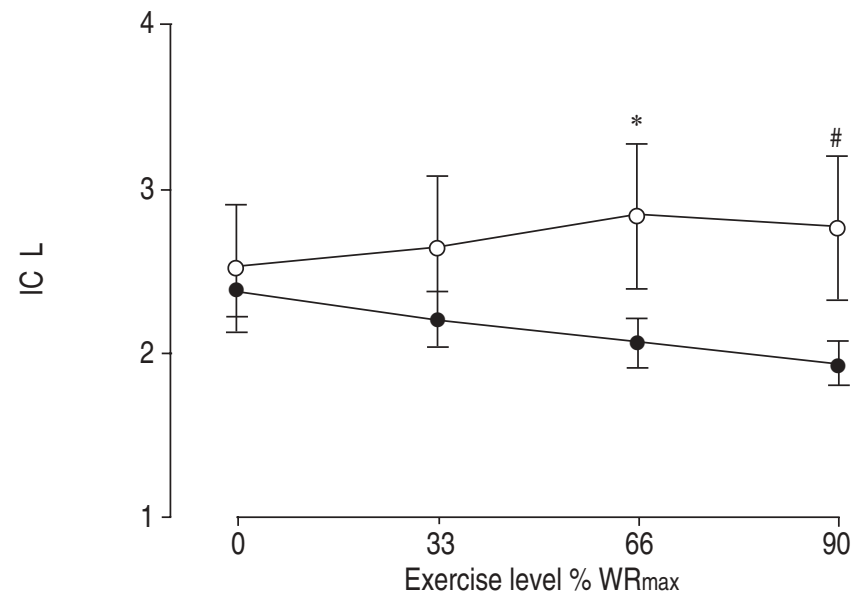

Fig. 2. - Inspiratory capacity (IC) in asthmatics with $(\bullet ; n=13)$ and without $(\bigcirc ; n=7)$ expiratory flow limitation $(E F L)$ at various levels of exercise. Data are presented as mean \pm SD. WRmax: maximal work rate. ${ }^{\#}: \mathrm{p}=0.03 ; *$ : $\mathrm{p}=0.05$ versus $\mathrm{EFL}$ (unpaired t-test).

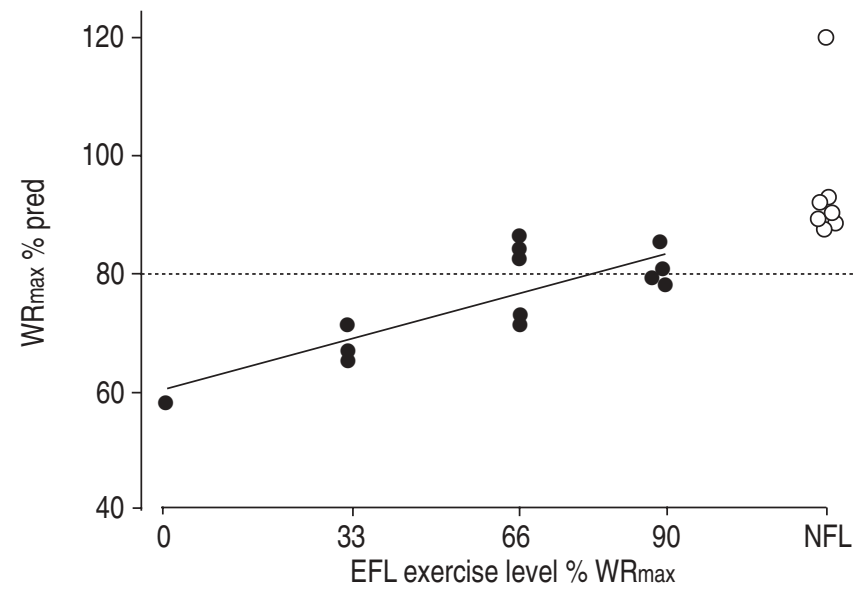

Fig. 3.-Relationship between maximal work rate (WRmax) and exercise level at which the asthmatics first exhibited expiratory flow limitation (EFL; 0 ). Each data point represents a single patient $(-$ : regression line pertaining to 13 EFL patients $(\mathrm{y}=60+0.25 \mathrm{x} \pm 5$ (SE); $\mathrm{r}=0.82, \mathrm{p}<0.001) ; \cdots \cdot$ : normal lower limit). In all non-EFL $(\mathrm{NFL})$ patients $(\bigcirc)$, WR $\max$ is within normal limits.

probably explains the reduction in exercise capacity in the patients who exhibited EFL during exercise. Indeed, as shown in figure 4 , there was significant correlation of WRmax and $V^{\prime} \mathrm{O}_{2}$, max to changes in IC (a marker of $\mathrm{DH}$ ) between rest and $90 \%$ WRmax. In addition, it is obvious that all $13 \mathrm{EFL}$ patients exhibited a decrease in IC (DH) between rest and 90\% WRmax, whereas six of the seven NFL patients showed an increase in IC.

Weak correlations were found of maximal $V^{\prime} \mathrm{E}\left(V^{\prime} \mathrm{E}, \mathrm{max} ; \%\right.$ pred) $(\mathrm{r}=0.55, \mathrm{p}=0.04), V^{\prime} \mathrm{E}, \max / \mathrm{MVV}(\mathrm{r}=-0.56, \mathrm{p}=0.04)$ and maximal tidal volume ( $\%$ pred $)(r=0.50, p=0.05)$ to the exercise level at which EFL first developed. Conversely, no significant correlation was found between the exercise level at which EFL first developed and the other cardiorespiratory responses studied, namely peak-exercise Borg score, maximal respiratory frequency, maximal $f \mathrm{C}(f \mathrm{C}, \max ), V^{\prime} \mathrm{O}_{2}, \max / f \mathrm{C}, \max$ and maximal arterial oxygen saturation measured by pulse oximetry.

The present patients showed a normal cardiac response to exercise since the exercise responses of anaerobic threshold, $f \mathrm{C}$, max and oxygen pulse were within the predicted limits. At any given exercise level, the Borg score tended to be higher in EFL than in NFL patients, although not significantly (fig. 5). This was also the case during peak exercise when the Borg scores of EFL and NFL subjects were $3.3 \pm 1.6$ and $2.3 \pm 2.2$, respectively, the difference being not significant. However, and according to one-way analysis of variance for repeated measures, EFL patients started to perceive significantly higher degrees of dyspnoea at $66 \%$ WRmax, whereas NFL patients only at $90 \%$ WRmax.

Only three of the present asthmatics exhibited EIA, as reflected by a fall in FEV1 of $\geqslant 15 \%$ at 5 and/or 15 min after exercise at $90 \% \mathrm{WRmax}$ [21]. One of them showed NFL and the other two developed EFL at 33 and $66 \%$ WRmax. This suggests that there is no clear association between EIA and EFL during exercise.

\section{Discussion}

The novel finding of the present study is that most stable asthmatic patients with normal resting spirometric results and without EIA exhibit tidal EFL and DH during exercise with a 

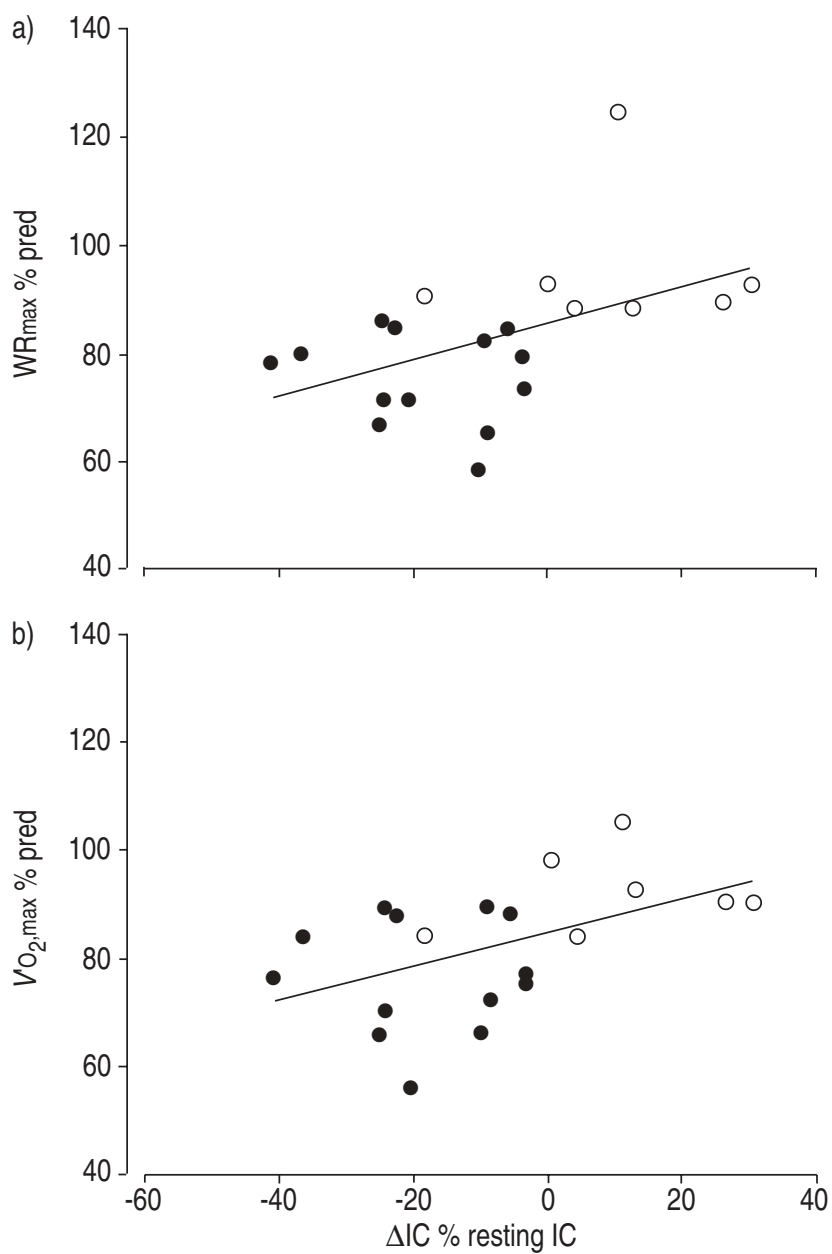

Fig. 4. - Relationship between a) maximal work rate (WRmax) and b) maximal oxygen uptake $\left(V^{\prime} \mathrm{O}_{2}, \max \right)$ and change in inspiratory capacity $(\Delta \mathrm{IC})$ from rest to $90 \% \mathrm{WR} \max$ in 20 asthmatic patients with $(\bullet)$ and without $(\bigcirc)$ tidal flow limitation during exercise. Each data point represents a single patient $(-$ : regression line; a) $y=85+0.3 \mathrm{x} \pm 13$ (SE); $\mathrm{r}=0.48, \mathrm{p}=0.04$; b) $\mathrm{y}=84+0.3 \mathrm{x} \pm 11$ (SE); $\mathrm{r}=0.48, \mathrm{p}=0.03$ ).

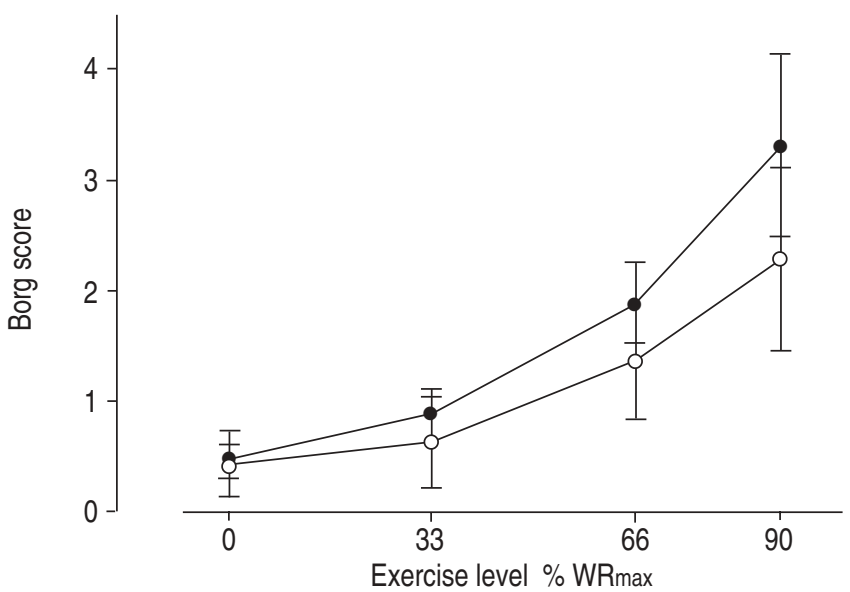

Fig. 5.-Asthmatic patients with expiratory flow limitation (EFL; -; $\mathrm{n}=13$ ) tended to have higher Borg dyspnoea scores throughout exercise than non-EFL patients (NFL; $\bigcirc$ ). Data are presented as mean \pm SD. EFL patients started to perceive significantly higher degrees of dyspnoea at $66 \%$ maximal work rate (WRmax), but NFL patients only at $90 \%$ WRmax (repeated-measures analysis of variance). concurrent reduction in exercise capacity, which probably reflects bronchoconstriction during exercise.

In line with previous studies using the NEP method $[12,13]$ it was found that, in asthmatics, tidal EFL is rarely found at rest. Indeed, only one of the present 20 patients showed EFL at rest. This was one of the three patients whose FEV1 and PEF were below the normal limits (fig. 1). In the other two patients with abnormal spirometric results, EFL first occurred at $33 \%$ WRmax. In 10 of the 17 patients whose FEV1 and PEF were within normal limits, tidal EFL occurred during exercise, whereas, in the other seven, it was absent $\leqslant 90 \%$ WRmax.

The observation that some, but not all, asthmatics with normal baseline spirometric results exhibited tidal EFL during exercise is probably related to the fact that some asthmatics exhibit bronchoconstriction during exercise [21-26], whereas others do not [26-28]. BECK et al. [22] had shown that, in asthmatics, there was a reduction in FEV1 during exercise and, subsequently, also demonstrated that, during interval and constant-load exercise, asthmatics exhibit a reduced ventilatory reserve, as well as a higher endexpiratory lung volume (i.e. $\mathrm{DH}$ ), compared to nonasthmatics [23]. SumAn et al. [25] have also documented a decrease in FEV1 and PEF accompanied by an increase in pulmonary resistance during exercise. It should be noted, however, that, in these studies [22, 23, 25], all of the subjects investigated had EIA.

Pulmonary hyperinflation, as reflected by decreased IC, was present during exercise in $70 \%$ of the present patients, whereas, in the remaining $30 \%$, the IC increased at all levels of constant-load exercise (fig. 2). It is tempting to suggest that the previous responses may depend on airway responsiveness to bronchoconstrictor challenge. Unfortunately, at the time of the study, airway reactivity to methacholine challenge was not assessed in the present patients. It should be noted, however, that, during methacholine-induced bronchoconstriction, $\mathrm{DH}$, as reflected by decreased IC, commonly occurs in the absence of tidal EFL [29]. In contrast, it was found that, during exercise, DH was closely associated with tidal EFL. This discrepancy may be due to the fact that, during methacholine challenge, $\mathrm{DH}$ is attributed to increased expiratory resistance associated with persistent activity of the inspiratory muscles during the breathing cycle [30-33] and expiratory narrowing of the glottis [34]. Although some of these mechanisms may have contributed to the exercise-induced $\mathrm{DH}$ in the present patients, EFL seems to be the principal factor, since it was present in all of the patients who exhibited DH, whereas it was absent in all patients who did not exhibit DH. It is possible that the exercise-induced bronchoconstriction within the lungs is more homogeneous than that induced by methacholine [35]. With nonhomogeneous bronchoconstriction, some regions may develop EFL with concurrent $\mathrm{DH}$, whilst others empty normally; hence, overall EFL (as measured using the NEP technique) may be absent. In such cases, IC may be decreased in the absence of overall EFL. In contrast, with homogeneous bronchoconstriction, overall EFL and DH should reflect the homogeneously distributed mechanical impairment within the lungs. In this connection, it should be noted that, although regional EFL may have been present in the seven patients who did not exhibit overall EFL during exercise, their IC increased progressively with increasing exercise intensity (fig. 2) as in normal subjects [10]. At peak exercise, however, one of these seven NFL subjects showed a reduction in IC (fig. 4), and it may be that this subject is a paradigm of nonhomogeneous bronchoconstriction, despite the challenge of exercise, multiregional EFL, the absence of overall EFL and DH.

In line with previous studies [2-7], it was found that, in asthmatics with an FEV1 and PEF below the normal limits, 
exercise capacity is reduced. Furthermore, the present results show that exercise intolerance is also common in asthmatics with normal baseline spirometric results and without EIA. These are the patients who developed tidal EFL during exercise (fig. 3). In contrast, in all asthmatics who did not exhibit EFL $\leqslant 90 \%$ WRmax, exercise capacity was within normal limits. The decreased exercise capacity in the EFL patients was associated with pulmonary hyperinflation (fig. 2). Indeed, there was a significant correlation of changes in IC to WRmax and $V^{\prime} \mathrm{O}_{2}$, max (fig. 4).

Since the presence of EFL implies increased expiratory impedance with concurrent increase in intrathoracic pressure during exercise and a decrease in cardiac output [36], it is conceivable that this may have contributed to the reduction in exercise capacity, at least in the three subjects with reduced FEV1 and PEF [37]. However, in all of these subjects, $f \mathrm{C}$, max (\% pred) and the anaerobic threshold were within normal limits, and the oxygen pulse was only slightly reduced $(76 \%$ pred) in two of them.

As shown in table 2, $V^{\prime}$ E, max/MVV (\%) was relatively low in all subjects. Indeed, even in the EFL patients, $V^{\prime} \mathrm{E}, \max /$ MVV amounted to only $59 \pm 13 \%$, suggesting that a large respiratory reserve was still available at peak exercise. In reality, however, these low values were based on MVV calculated using the pre-exercise resting FEV1. It is highly likely, however, that the present EFL subjects developed bronchoconstriction during exercise with a concomitant decrease in FEV1 and calculated MVV, implying less respiratory reserve. This implies that, in future studies, FEV1 should be measured throughout exercise.

As previously reported for asthmatics [20, 38], Borg scores during exercise were relatively low (fig. 5). This may be related to the fact that score 10 on the Borg scale is anchored to the "most severe breathlessness that you have ever experienced" (see Methods section). Since, unlike other patients, most asthmatics experience acute episodes (attacks) characterised by most severe breathlessness, they may perceive a relatively low sensation of dyspnoea during exercise and, hence, the Borg scores are low. On average, during exercise and under conditions of the same work rate, the EFL patients exhibited greater Borg scores than the NFL patients (fig. 5), but the differences were not significant. However, EFL patients started to perceive significantly higher degrees of dyspnoea at earlier stages of exercise intensity $(66 \%$ WRmax), but NFL patients only at 90\% WRmax.

In the present study, MRC chronic dyspnoea scores were very low (range $0-1)$. Low MRC scores (1.4 \pm 1.8 ) were also found by BocZKowsKi et al. [12] in 13 asthmatics, in whom FEV1 was lower than those found in the present study $(68 \pm 16 \%$ pred). None of their patients exhibited tidal EFL sitting at rest. According to ElTAYARA et al. [8] and at least in COPD patients, high MRC dyspnoea scores ( $>2$ ) are, in general, claimed only by patients who exhibit tidal EFL sitting at rest.

No association between EIA and exercise capacity was observed. EIA is a widely studied entity with a characteristic clinical pattern, which has been attributed to inspiration of dry and cold air during exercise and to airway rewarming after exercise [21]. It is characterised by maximal obstruction occurring 5-15 min after the cessation of exercise. Spontaneous remission usually follows, such that lung function returns to baseline levels within $30-60 \mathrm{~min}$. The results of the present study suggest that the two phenomena, namely EFL during exercise and EIA, are distinct entities.

In conclusion, the present results show that most patients with stable asthma exhibit tidal expiratory flow limitation and dynamic hyperinflation during exercise, even if their baseline forced expiratory volume in one second and peak expiratory flow are within normal limits and they have no exercise-induced asthma. In asthmatics with exercise-induced tidal expiratory flow limitation, the exercise capacity is reduced as a result of dynamic hyperinflation. This finding has important clinical implications because it is possible that the administration of bronchodilators immediately before exercise may abolish tidal expiratory flow limitation and dynamic hyperinflation during exercise and improve exercise capacity. With this connection, it should be remembered that, in the present study, patients refrained from using bronchodilators prior to the investigation.

\section{References}

1. NHLBI/WHO Workshop Report. Global Strategy for Asthma Management and Prevention. www.ginasthma.com. Date last updated: November, 2003. Date last accessed: February, 2004.

2. Murariu C, Ghezzo H, Milic-Emili J, Gautier H. Exercise limitation in obstructive lung disease. Chest 1998; 114: 965-968.

3. Boulet LP, Turcotte H, Hudon C, Carrier G, Maltais F. Clinical, physiological and radiological features of asthma with incomplete reversibility of airflow obstruction compared with those of COPD. Can Respir J 1998; 5: 270-277.

4. Foglio K, Carone M, Pagani M, Bianchi L, Jones PW, Ambrosino N. Physiological and symptom determinants of exercise performance in patients with chronic airway obstruction. Respir Med 2000; 94: 256-263.

5. Hallstrand TS, Bates PW, Schoene RB. Aerobic conditioning in mild asthma decreases the hyperpnea of exercise and improves exercise and ventilatory capacity. Chest 2000; 118 : 1460-1469.

6. Satta A. Exercise training in asthma. J Sports Med Phys Fitness 2000; 40: 277-283.

7. Cooper CB. Exercise in chronic pulmonary disease: limitations and rehabilitation. Med Sci Sports Exerc 2001; 33: Suppl. 7, S643-S646.

8. Eltayara L, Becklake MR, Volta CA, Milic-Emili J. Relationship between chronic dyspnoea and expiratory flow limitation in patients with chronic obstructive pulmonary disease. Am J Respir Crit Care Med 1996; 154: 1726-1734.

9. Diaz O, Villafranca C, Ghezzo $\mathrm{H}$, et al. Role of inspiratory capacity on exercise tolerance in COPD patients with and without tidal expiratory flow limitation at rest. Eur Respir $J$ 2000; 16: 269-275.

10. Koulouris NG, Dimopoulou I, Valta P, Finkelstein R, Cosio MG, Milic-Emili J. Detection of expiratory flow limitation during exercise in COPD patients. J Appl Physiol 1997; 82: 723-731.

11. Diaz O, Villafranca C, Ghezzo H, et al. Breathing pattern and gas exchange at peak exercise in COPD patients with and without tidal flow limitation at rest. Eur Respir $J$ 2001; 17: $1120-1127$.

12. Boczkowski J, Murciano D, Pichot MH, Ferretti A, Pariente R, Milic-Emili J. Expiratory flow limitation in stable asthmatic patients during resting breathing. Am J Respir Crit Care Med 1997; 156: 752-757.

13. Baydur A, Milic-Emili J. Expiratory flow limitation during spontaneous breathing: comparison of patients with restrictive and obstructive respiratory disorders. Chest 1997; 112: 1017-1023.

14. Quanjer PH, Tammeling GJ, Cotes JE, Pedersen OF, Peslin R, Yernault JC. Standardized lung function testing. Eur Respir J 1993; 6: Suppl. 16, 1-99.

15. American Thoracic Society/American College of Chest Physicians. ATS/ACCP Statement on cardiopulmonary exercise testing. Am J Respir Crit Care Med 2003; 167: 211-277.

16. Jones NL. Clinical Exercise Testing. 3rd Edn. Philadelphia, WB Saunders Co., 1988.

17. Borg GAV. A ratio scaling method for interindividual comparisons. Reports from the Institute of Applied Psychology. University of Stockholm. 1972; 27: 1-12. 
18. McFadden ER Jr. Exercise performance in the asthmatic Am Rev Respir Dis 1994; 129: Suppl. 2, S84-S87.

19. Folgering H, Palange $\mathrm{P}$, Anderson S. Clinical exercise testing with reference to lung diseases: indications and protocols. Eur Respir Mon 1997; 2 (Monograph 6), 51-71.

20. Banzett RB, Dempsey JA, O'Donnell DE, Wamboldt MZ Symptom perception and respiratory sensation in asthma. Am J Respir Crit Care Med 2000; 162: 1178-1182.

21. Cypcar D, Lemanske RF Jr. Asthma and exercise. Clin Chest Med 1994; 15: 351-368.

22. Beck KC, Offord KP, Scanlon PD. Bronchoconstriction occurring during exercise in asthmatic subjects. Am J Respir Crit Care Med 1994; 149: 352-357.

23. Johnson BD, Scanlon PD, Beck KC. Regulation of ventilatory capacity during exercise in asthmatics. $J$ Appl Physiol 1995; 79: 892-901.

24. Beck KC, Hyatt RE, Mpougas P, Scanlon PD. Evaluation of pulmonary resistance and maximal expiratory flow measurements during exercise in humans. J Appl Physiol 1999; 86: $1388-1395$.

25. Suman OE, Beck KC, Babcock MA, Pegelow DF, Reddan WG. Airway obstruction during exercise and isocapnic hyperventilation in asthmatic subjects. J Appl Physiol 1999; 87: 1107-1113.

26. Haas F, Pineda H, Axen K, Gaudino D, Haas A. Effects of physical fitness on expiratory airflow in exercising asthmatic people. Med Sci Sports Exerc 1985; 17: 585-592.

27. Anderson SD. Exercise-induced asthma. In: Middleton E, Reed CE, Ellis EF, eds. Allergy: principles and practice. 4th Edn. St Louis, MO, CV Mosby, 1993; pp. 1343-1360.

28. Crimi E, Pellegrino R, Smeraldi A, Brusasco V. Exerciseinduced bronchodilation in natural and induced asthma: effects on ventilatory response and performance. $J$ Appl Physiol 2002; 92: 2353-2360.

29. Tantucci C, Ellaffi M, Duguet A, et al. Dynamic hyperinflation and flow limitation during methacholine-induced bronchoconstriction in asthma. Eur Respir J 1999; 14: 295-301.

30. Gorini M, Iandelli I, Misuri G, et al. Chest wall hyperinflation during acute bronchoconstriction in asthma. $\mathrm{Am}$ J Respir Crit Care Med 1999; 160: 808-816.

31. Martin JG, Powell E, Shore S, Emrich J, Engel LA. The role of respiratory muscles in the hyperinflation of bronchial asthma. Am Rev Respir Dis 1980; 121: 443-447.

32. Muller N, Bryan AC, Zamel N. Tonic inspiratory muscle activity as a cause of hyperinflation in histamine-induced asthma. J Appl Physiol 1980; 49: 869-874.

33. Cormier Y, Lecours R, Legris C. Mechanisms of hyperinflation in asthma. Eur Respir J 1990; 3: 619-624.

34. Collett PW, Brancatisano T, Engel LA. Changes in glottic aperture during bronchial asthma. Am Rev Respir Dis 1983; 128: 719-723

35. Pellegrino R, Biggi A, Papaleo A, Camuzzini G, Rodarte JR, Brusasco V. Regional expiratory flow limitation studied with Technegas in asthma. J Appl Physiol 2001; 91: 2190-2198.

36. Pepe PE, Marini JJ. Occult positive end-expiratory pressure in mechanically ventilated patients with airflow obstruction: the auto-PEEP effect. Am Rev Respir Dis 1982; 126: 166-170.

37. Varray A, Mercier J, Savy-Pacaux A-M, Prefaut C. Cardiac role in exercise limitation in asthmatic subjects with special reference to disease severity. Eur Respir J 1993; 6: 1011-1017.

38. Killian KJ, Summers E, Watson RM, O'Byrne PM, Jones NL, Campbell EJM. Factors contributing to dyspnoea during bronchoconstriction and exercise in asthmatic subjects. Eur Respir J 1993; 6: 1004-1010. 